\title{
A COMBINED STRABISMUS HOOK AND MUSCLE CLAMP
}

\author{
BY
}

\section{T. HARRISON BUTLER}

BIRMINGHAM

IT is not always easy in a small child to introduce a muscle clamp under the internal rectus muscle when the somewhat limited space is already occupied by a strabismus hook. The manoeuvre is frequently attended with some pain caused by the unavoidable traction upon the muscle. I suggested to Messrs. Weiss the lines along which the two instruments might be combined. After several trials the combined instrument shown in the figure has been devised and perfected. The distal hook has the shape and

size of an ordinary right-angled strabismus hook, but is pierced by three holes. A second hook furnished with three* sharp pins, as in Prince's clamp, slides upon the first, and the pins register with the holes. When pushed home the clamp is automatically locked but can be easily released by pressure upon a spring-loaded button. The handle is serrated to afford a good grip to a gloved hand. The instrument can be supplied in two sizes but I prefer the smaller of the two. The instrument is equally applicable to advancement or recession of any of the four recti. I have given it an extended trial and I find that it greatly facilitates and shortens a squint operation. I am accustomed to operate even upon small children under local anaesthesia. A few drops of codrenine are injected under the conjunctiva over the muscles to be operated upon and if no traction be made upon them the procedure is painless. The slightest pull upon the muscle causes the child to complain, not of local pain, but of headache. The new hook has reduced the chance of traction to a minimum. Care must be taken when using the hook to find the muscle that the slide is pushed well back to avoid the possibility of the sharp pins scratching the cornea.

\footnotetext{
* The small size of hook has two pins, the large one, as illustrated, three.
} 